\title{
Saúde mental em pauta: afirmação do cuidado em liberdade e resistência aos retrocessos
}

Reafirmando nosso compromisso com a Reforma Psiquiátrica, com a produção de conhecimento científico implicado com a atenção psicossocial e com a história do movimento da Luta Antimanicomial, apresentamos nosso posicionamento referente à Nota Técnica no 11/2019, emitida pela Coordenação Geral de Saúde Mental, Álcool e Outras Drogas - CGMAD/DAPES/SAS/MS, em 04 de fevereiro de 2019, que acelera o processo das mudanças na indução das políticas de saúde mental iniciadas no final de 2017.

Embora a referida Nota já tenha sido oficialmente retirada pelo Ministério da Saúde por força das pressôes sociais, compreendemos que as intenções políticas e técnicas anunciadas pela atual Coordenação Nacional de Saúde Mental continuam sendo cotidianamente atualizadas por seus posicionamentos públicos, bem como pela emissão das Portarias e Resoluçóes, que apontam para importantes retrocessos das Políticas de Saúde Mental brasileiras. Além disso, tomamos esta Nota como um importante dispositivo analisador ${ }^{1}$ dos discursos e práticas psiquiátricas que ganham força a partir do crescimento, no Brasil, de uma nova "onda conservadora", um movimento de forças que tem atuado explicitamente a favor da contenção de direitos garantidos desde a Constituição de 1988 (ALMEIDA, 2017).

Para sintetizar as análises e o nosso posicionamento, apresentaremos este texto em três planos principais: O plano acadêmico e da produção de conhecimento; o plano técnico e o plano ético-político - este último transversal aos outros dois - com a clareza de que esses planos se retroalimentam e se produzem de forma indissociável.

No que se refere ao âmbito acadêmico, a Nota explicita que

[...] o Ministério da Saúde passa a aprimorar o monitoramento e acompanhamento da política, [...] para que o atendimento aos pacientes acompanhados na RAPS seja embasado em evidências científicas (BRASIL, 2019, p. 5-6).

Estabelece ainda que na

[...] nova Política Nacional de Saúde Mental [...] a assistência em Saúde Mental no SUS deverá seguir as melhores práticas clínicas e as mais robustas e recentes evidências científicas (BRASIL, 2019, p. 6).

Como exemplo, a Nota cita a retomada da Eletroconvulsoterapia (ECT), cujo aparelho passou a compor a lista de Equipamentos e Materiais do Fundo Nacional de Saúde, apesar de seu uso náo ser um consenso no meio acadêmico e, comprovadamente, ter tido o uso histórico vinculado às práticas indiscriminadas, punitivas e de tortura em instituiçóes psiquiátricas, um dos motivos pelos quais foi intensamente questionada e contraindicada pelo movimento da Reforma Psiquiátrica na direção da defesa dos direitos humanos dos usuários.

É preciso destacar que, o discurso científico, é historicamente um discurso produzido por disputas de saber-poder de diferentes epistemologias e disciplinas, que atendem a interesses diversos e a concepçóes de mundo que não são estanques, como nos ajudou a compreender Foucault (1972) em suas análises filosóficas da História da Loucura, que partiram justamente de um mergulho empírico nas instituiçóes psiquiátricas.

Explicitamente alinhada com as evidências acadêmicas produzidas no campo da Biomedicina dominante e no método da Medicina baseada em evidências, a Nota expressa completo desconhecimento em relação à vasta produção científica que embasa as práticas e Políticas de Atenção Psicossocial oriundas de campos plurais como a Psiquiatria Democrática, a Saúde Coletiva, a Psicologia, a Enfermagem, a Terapia Ocupacional e as Ciências Sociais e Humanas em geral, entre outros, além de uma desconexão com as construçóes de evidências qualitativas e participativas, amplamente validadas e incorporadas na construção das Políticas norteadoras da Rede de Atenção Psicossocial (CAMPOS et al., 2013). Sinteticamente, essas evidências, entre outras coisas, apontam consensualmente para o caráter iatrogênico e ineficiência dos tratamentos de 
caráter asilar ou segregacionistas; para a eficácia clínica dos tratamentos comunitários, especialmente em territórios nos quais a rede de saúde mental substitutiva está consolidada e para a importância do caráter interdisciplinar e intersetorial das intervençôes e da constituição das equipes profissionais.

No plano técnico, é preciso combater a ideia corrente de que a Reforma Psiquiátrica, incorporada como política de Estado, se pauta exclusivamente por princípios ideológicos. Sem nenhum demérito à ideologia (igualmente presente na Nota Técnica e em tantas ações de governança), é preciso salientar que a RAPS, como política pública de saúde está amplamente ancorada em técnicas e tecnologias desenvolvidas no campo da saúde mental, saúde coletiva e correlatos, em açóes desenvolvidas a partir da experiência clínica de milhares de profissionais e da experiência de tratamento de milhares de usuários e familiares em articulação com Universidades e outras instituiçóes que se colocam como atores das Políticas Sociais.

Desenvolveram-se sólidos arranjos e dispositivos de cuidado que se articularam na afirmação de um modelo de Saúde Mental que só pôde ser construído por uma convergência de prioridades orçamentárias que garantiram um investimento progressivo em serviços substitutivos e regressivo em relação às instituições asilares ou aos Hospitais Psiquiátricos monovalentes. Entre esses equipamentos substitutivos encontram-se os Centros de Atenção Psicossocial (CAPS), os Centros de Convivência (CECOS), as iniciativas de Inclusão Social pelo Trabalho e as Residências Terapêuticas (que a partir do Programa de Volta para Casa viabilizou a desinstitucionalização de milhares de moradores de hospitais psiquiátricos - HPs, que são testemunhas vivas das atrocidades que a Psiquiatria impôs a centenas de vidas na recente história dos manicômios brasileiros). Nestes dispositivos foi desenvolvido um amplo conjunto de tecnologias de cuidado comprometidas com a eficácia clínica, com a preservação/construção de laços socio-afetivos como eixo-chave das açôes em saúde mental, com o enfrentamento das situaçôes de exclusão social e com a garantia de direitos dos usuários. Esses processos, que se realizaram a partir do trabalho de muitas pessoas, nos encontros entre profissionais, usuários e familiares, estavam em franco processo de implementação e expansão desde a década de 1990 até 2016.

A partir do Governo Temer, e com forte expressão na Nota Técnica, foi apontado um grave redirecionamento dos recursos orçamentários para os HPs (que voltam a compor os serviços da RAPS, sem aprovação do Conselho Nacional de Saúde e das demais instâncias de participação social, como o movimento da Luta Antimanicomial). Vale reforçar que o retorno dos HPs como parte integrante da rede, inclui também leitos para crianças e adolescentes, ferindo a garantia de direitos desta populaçáo reafirmados no Estatuto da Criança e do Adolescente.

$\mathrm{Na}$ mesma direção, há uma guinada na política de atenção às pessoas com problemas de uso abusivo de álcool e outras drogas, no sentido de redirecionar os objetivos dos tratamentos para a lógica da abstinência, a ser viabilizada em instituiçôes fechadas, preferencialmente as Comunidades Terapêuticas - CTs (que são majoritariamente geridas por instituiçôes de cunho religioso e que não compartilham de evidências científicas, sejam elas biomédicas ou do campo da Reabilitação Psicossocial, para a construção de suas práticas). Deixam de ser priorizadas a abordagem da Redução de Danos e os CAPS AD como estratégias principais no acompanhamento dessas pessoas.

A resistência às CTs e à centralidade das açôes de saúde mental nos Hospitais Psiquiátricos não se constitui na negação do fato de que existem situações que exigem um aparato de hospitalidade integral, continência e suporte às famílias, especialmente em casos de usuários em crise, com alto grau de vulnerabilidade e em situações de risco pessoal-social. A atenção à crise deve ser prioritariamente construída pelos CAPS III e pela garantia de leitos de saúde mental em Hospitais Gerais, preservando o convívio social das pessoas.

Essas mudanças aventadas, e em parte já incorporadas na máquina do Estado, representam retrocessos importantes e vão na contramáo de todas as políticas globais que alcançaram bons indicadores epidemiológicos de Saúde Mental e nos dáo brechas para compreender as inflexôes que elas representam no plano éticopolítico, principalmente, no tocante à garantia de direitos humanos, como já assinalada anteriormente.

Como terapeutas ocupacionais e pesquisadoras, salientamos que a Terapia Ocupacional é uma profissão historicamente comprometida com a Reforma Psiquiátrica e com o movimento da Luta Antimanicomial, formando profissionais implicados com a inclusão social e com a emancipação de sujeitos individuais e coletivos. Posicionamos-nos a favor da "universalização dos direitos sociais, o respeito e a promoção da liberdade, da dignidade, da igualdade e da integridade do ser humano" contribuindo para a "eliminaçáo de quaisquer formas de negligência, discriminação, exploração, violência, crueldade e opressão", conforme explícito na resolução 425 do Conselho Federal de Fisioterapia e Terapia Ocupacional (CONSELHO..., 
2013, s/p). Neste sentido, não negamos que existam limites e aspectos da Reforma Psiquiátrica que precisam ser revistos e transformados, no entanto, a precariedade de parcela da rede (explicada em parte pelo subfinanciamento crônico do SUS), não pode ser usada como justificativa para o rebaixamento da vida que se expressa no retrocesso conceitual, técnico e ético-político que a "nova política" de saúde mental aponta.

\section{Isabela Aparecida de Oliveira Lussi, Sabrina Helena Ferigato, \\ Alana de Paiva Nogueira Fornereto Gozzi, Amanda Dourado Souza Akahosi Fernandes, Giovana Garcia Morato, Maria Fernanda Barboza Cid, Paula Giovana Furlan, Taís Quevedo Marcolino, Thelma Simóes Matsukura}

Laboratório de Pesquisa em Terapia Ocupacional e Saúde Mental - LaFollia, Departamento de Terapia Ocupacional, Universidade Federal de São Carlos - UFSCar, São Carlos, SP, Brasil.

\section{Referências}

ALMEIDA, R. A onda quebrada - evangélicos e conservadorismo. Cadernos Pagu, Campinas, n. 50, p.1-27, 2017. http://dx.doi.org/10.1590/18094449201700500001.

ARDOINO, J.; LOURAU, R. As pedagogias institucionais. São Carlos: RiMa, 2003.

BRASIL. Ministério da Saúde. Secretaria de Atenção à Saúde. Nota Técnica no 11/2019. Esclarecimentos sobre as mudanças na Política Nacional de Saúde Mental e nas Diretrizes da Política Nacional sobre Drogas. Brasília: Ministério da Saúde, 2019. Disponível em: <http://pbpd.org.br/wp-content/uploads/2019/02/0656ad6e.pdf>. Acesso em: 01 mar. 2019.

CAMPOS, G. W. S.; ONOCKO-CAMPOS, R. T.; DEL BARRIO, L. R. Políticas e práticas em saúde mental: as evidências em questão. Ciência \& Saúde Coletiva, Rio de Janeiro, v. 18, n. 10, p. 2797-2805, 2013. http://dx.doi. org/10.1590/S1413-81232013001000002.

CONSELHO FEDERAL DE FISIOTERAPIA E TERAPIA OCUPACIONAL - COFFITO. Resolução no 425 de 8 de julho de 2013. Estabelece o Código de Ética e Deontologia da Terapia Ocupacional. Diário Oficial [da] República Federativa do Brasil, Poder Executivo, Brasília, DF, 01 ago. 2013. Seção 1. Disponível em: <https://www.coffito.gov. br/nsite/?p=3188>. Acesso em: 07 mar. 2019.

FOUCAULT, M. Histoire de la folie à l'Âge Classique. Paris: Gallimard, 1972.

\section{Notas}

1 “Analisadores são acontecimentos ou fenômenos aparentemente 'insignificantes', mas portadores do sentido oculto do nâo dito” (ARDOINO; LOURAU, 2003, p. 14). 